\title{
Pediatric medulloblastoma express immune checkpoint B7-H3
}

\author{
S. Li ${ }^{1}$ - G. C. Poolen ${ }^{1} \cdot$ L. C. van Vliet ${ }^{1}$. J. G. Schipper ${ }^{1} \cdot$ R. Broekhuizen ${ }^{1} \cdot$ M. Monnikhof ${ }^{1} \cdot$ W. Van Hecke ${ }^{1}$. \\ J. F. Vermeulen ${ }^{1} \cdot$ N. Bovenschen ${ }^{1,2}$
}

Received: 11 September 2021 / Accepted: 15 December 2021 / Published online: 5 January 2022 (c) The Author(s) 2022

\begin{abstract}
Purpose Medulloblastomas (MB) are highly malignant brain tumors that predominantly occur in young infants. Immunotherapy to boost the immune system is emerging as a novel promising approach, but is often hampered by inhibitory immune checkpoints. In the present study, we have studied immune checkpoint B7-H3 expression in a tissue cohort of human pediatric MB.

Methods Expression of B7-H3 was detected by immunohistochemistry and classified via B7-H3 staining intensity and percentage of B7-H3 positive tumor cells. Subsequently, B7-H3 protein expression was distinguished in MB molecular subtypes and correlated to immune cell infiltrates, patient characteristics, and survival.

Results B7-H3 protein expression was found in 23 out of 24 (96\%) human pediatric MB cases and in 17 out of 24 (71\%) MB cases $>25 \%$ of tumor cells had any level of B7-H3 expression. B7-H3 protein expression was more frequent on Group-4 MB as compared with other molecular subtypes $(p=0.02)$. Tumors with high B7-H3 expression showed less influx of $\gamma \delta \mathrm{T}$ cells $(p=0.002)$ and $\mathrm{CD} 3+\mathrm{T}$ cells $(p=0.041)$.

Conclusion Immune checkpoint B7-H3 is differentially expressed by the large majority of pediatric MB. This further warrants the development of novel B7-H3-directed (immuno)therapeutic methods for children with incurable, metastatic, or chemo-resistant MB.
\end{abstract}

Keywords Pediatric medulloblastoma $\cdot$ Brain cancer $\cdot$ Immune checkpoint $\cdot$ Immunotherapy

\section{Introduction}

Medulloblastoma (MB) is the most common malignant brain tumor that typically occurs during childhood, accounting for $20-25 \%$ of all pediatric brain tumors world-wide [1]. Clinical treatment of MB is limited to neurosurgical removal of the tumor and radiation therapy, together with chemotherapy [2]. Relatively late diagnosis, metastasis, long-term side effects, and high rate of relapses are factors that contribute to low survival chances of MB patients [2]. In general, defined molecular subgroups of MB are wingless (WNT, about $10 \%$ of MB cases), sonic hedgehog ( $\mathrm{SHH}$, about $30 \%$

N. Bovenschen

n.bovenschen@umcutrecht.nl

1 Department of Pathology, University Medical Center Utrecht, Heidelberglaan 100, 3584 CX Utrecht, The Netherlands

2 Center for Translational Immunology, University Medical Center Utrecht, 3584 CX Utrecht, The Netherlands of MB cases), group 3 (about $25 \%$ of cases), and group 4 (about $35 \%$ of cases) [2]. Prognostic outcome of MB patients depend on the molecular features of these subgroups, with extremely favorable prognosis for WNT tumors, intermediate outcomes for $\mathrm{SHH}$ and group 4 tumors, and poor prognosis for group 3-driven MB [2].

Immunotherapy with immune checkpoint inhibitors to enhance the immune response is emerging as a promising novel therapy to improve survival and to avoid relapses in brain cancer. For instance, blocking PD1-PD-L1 immune checkpoints with antibodies (e.g. nivolumab and pembrolizumab) result in improved therapy response in non-small cell lung cancer (NSCLC), melanoma, and their corresponding brain metastases [3, 4]. PD-L1 is also expressed by several brain cancers, including glioblastoma, and clinical trials are ongoing. However, PD-L1 expression by MB is limited if not absent [5], indicating that interfering with the PD-1/PD-L1 axis may not be feasible in MB. The expression landscape of immune checkpoints on MB remains unclear. Recently, immune checkpoint B7-H3 (CD276) has been 
detected on the plasma membrane of MB cells [6-9]. As such, B7-H3 might be an interesting therapeutic target for blocking antibodies or for chimeric antigen receptor (CAR) $\mathrm{T}$ cell therapy [7]. However, the evidence of B7-H3 expression by MB is based on limited cases, cell lines instead of tissue, non-validated antibodies for B7-H3 detection [6, 8], single scoring systematics, lack of correlation with molecular tumor subtype, clinical data or microenvironment, or via analyses on $0.6-1 \mathrm{~mm}$ cancer tissue cores in a tissue microarray $[7,10]$

In the present study, we determined immune checkpoint B7-H3 protein expression in MB, using a knockout-validated anti-B7-H3 antibody in immunohistochemistry on whole tissue slides of 24 pediatric MB cases. Furthermore, we have distinguished $\mathrm{B} 7-\mathrm{H} 3$ protein expression in MB molecular subtypes and correlated these to immune cell infiltrates, patient characteristics, and survival.

\section{Materials and methods}

\section{Patients}

Our cohort of pediatric MB has been described by Vermeulen et al. [11]. The study material was derived from the archive of the Department of Pathology of the University Medical Center Utrecht, Utrecht, The Netherlands and distributed by the Biobank of the Department of Pathology that is overseen by the institutional medical ethical review board. Since we use archival pathology material which does not interfere with patient care and does not involve physical involvement of the patient, no ethical approval is required according to Dutch legislation. Use and storage of anonymous or coded left over material for scientific purposes is part of the standard treatment contract with patients and therefore informed consent procedure was not required according to our institutional medical ethical review board.

\section{Immunohistochemistry}

Immunohistochemistry was carried out on $4 \mu \mathrm{m}$ thick formalin-fixed, paraffin-embedded sections as we described [12]. Briefly, endogenous peroxidase activity was blocked for $15 \mathrm{~min}$ in a buffer containing $0.3 \%$ hydrogen peroxide. After antigen retrieval, i.e. boiling for $20 \mathrm{~min}$ in $10 \mathrm{mM}$ citrate $\mathrm{pH6.0}$, or Tris/EDTA pH9.0. After boiling for $20 \mathrm{~min}$ in $10 \mathrm{mM}$ citrate $\mathrm{pH} 6.0$, staining was performed with B7-H3(CD276) antibody (NBP1-88966, Novus Biologicals, Littleton, USA; knockout-validated; 1:70) in PBS containing $2 \% \mathrm{BSA}$ for $1 \mathrm{~h}$ at room temperature. The signal was amplified using Bright vision poly-HRP anti-rabbit (DPVOHRP, Immunologic) and developed with diaminobenzidine followed by counterstaining with haematoxylin, dehydration in alcohol and mounting. Appropriate positive and negative controls were included in all stainings.

\section{Scoring of immunohistochemistry}

Scoring and grading of immunohistochemistry was executed blindly by three independent observers, using the scoring table by Gregorio et al. [6]. The immunohistochemical results were classified via two different ways. One method was qualitatively scored as 0 in the absence of reactivity or $<10 \%$ of cells with membranous staining; score 1 in the presence of weak and partial membranous reactivity in $>10 \%$ of cells; score 2 when moderate membranous reactivity was detected in $>10 \%$ of cells; and score 3 when intense membranous reactivity occurred in $>10 \%$ of cells. Using another scoring method, reactivity was graded semiquantitatively as: \pm with $0-25 \%$ positive tumor cells; + with $25-50 \%$ positive tumor cells; ++ with $50-75 \%$ positive tumor cells; and +++ with $75-100 \%$ positive tumor cells.

\section{Statistical analysis}

Statistical analysis was performed using IBM SPSS version 23 (SPSS Inc.). A Median Split was used for turning a continuous variable into a categorical one. Any value below the median is put it the category 'Low' and any value above median labeled 'High'. Categorical data were analyzed using the Fisher's exact test (for gender and molecular classification). Immune cell infiltrates was analyzed using Pearson chi-squared test. Overall survival was used as outcome endpoint and defined as the time between date of

Table 1 Patient characteristics

\begin{tabular}{llr}
\hline & $N$ or value & $\%$ \\
\hline Gender & & \\
Male & 15 & 62.5 \\
Female & 9 & 37.5 \\
Age (years) & & \\
Mean \pm SD & $8.6 \pm 5.2$ & \\
Range & $0.4-17.8$ & \\
Histological type & & 58.3 \\
Classic & 14 & 25.0 \\
Desmoplastic nodular & 6 & 12.5 \\
Extensive nodular & 3 & 4.2 \\
Anaplastic & 1 & \\
Molecular classification & & 3.2 \\
WNT & 1 & 20.8 \\
SHH & 8 & 33.3 \\
Group 3 & 5 & 8.3 \\
Group 4 & 8 & \\
Undetermined & 2 & \\
\hline
\end{tabular}


surgery and death. Censored patients were confirmed alive at time of censoring. Survival data were analyzed using the Kaplan-Meier method and log-rank test, taking all patients into account. Statistical significance was set at $p<0.05$.

\section{Results}

We investigated B7-H3 expression in a cohort of human MB tissues (Table 1). B7-H3 expression was found in 23 out of $24 \mathrm{MB}$ cases $(96 \%)$ and in 17 out of $24(71 \%)$ tumors $>25 \%$ of tumor cells had any level of B7-H3 expression. Representative immunohistochemical stainings of $\mathrm{B} 7-\mathrm{H} 3$ are depicted in Fig. 1. First, tumors were scored for B7-H3 staining intensity and separated in four categories: (1) no membranous staining or any staining in $<10 \%$ of cells $(n=1)$, (ii) weak and partial membranous staining $(n=10)$, (iii) moderate membranous staining $(n=9)$, and (4) intense membranous staining ( $n=4)$ (Fig. 2A). Second, we determined the percentage of $\mathrm{B} 7-\mathrm{H} 3$ positive tumor cells: $<25 \%$

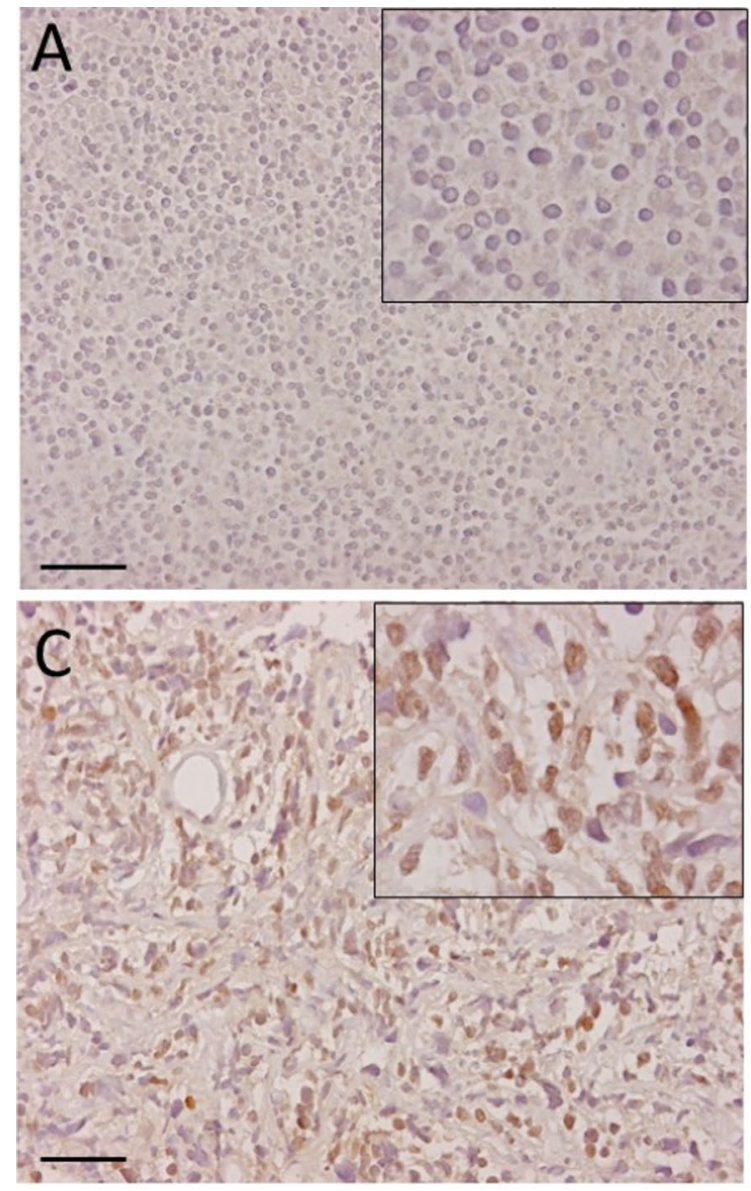

Fig. 1 Expression of B7-H3 in pediatric medulloblastoma. A B7-H3 expression scored with score 0 and grade \pm . B B7-H3 expression scored with score 1 and grade + . C B7-H3 expression scored with $(n=7), 25-50 \%(n=4), 50-75 \%(n=5)$, and $>75 \%(n=8)$ (Fig. 2B). B7-H3 protein expression was more frequent on group-4 MB as compared with other molecular subtypes $(p=0.02)$. No correlation was found between $\mathrm{B} 7-\mathrm{H} 3$ protein expression (reactivity score) and gender $(p=0.300)$, molecular subtypes $(p=0.077)$, or overall survival $(p=0.181)$. Previously, we have measured immune cell infiltrates in these MB tumor tissues, including CD3+ T cells, CD4+ T cells, CD8+ T cells, CD20+ B cells, NK cells, FOXP3+ regulatory $\mathrm{T}$ cells, and $\gamma \delta \mathrm{T}$ cells [11]. We found that tumors with a high B7-H3 score (2 or 3 ) showed less influx of $\gamma \delta \mathrm{T}$ cells $(p=0.002)$ and $\mathrm{CD} 3+\mathrm{T}$ cells $(p=0.041)$, whereas the influx of CD4- or CD8-positive T cells, B cells or NK cells was not correlated to B7-H3 expression (Table 2). In conclusion, we have demonstrated that immune checkpoint B7-H3 is differentially expressed by the large majority of pediatric MB.
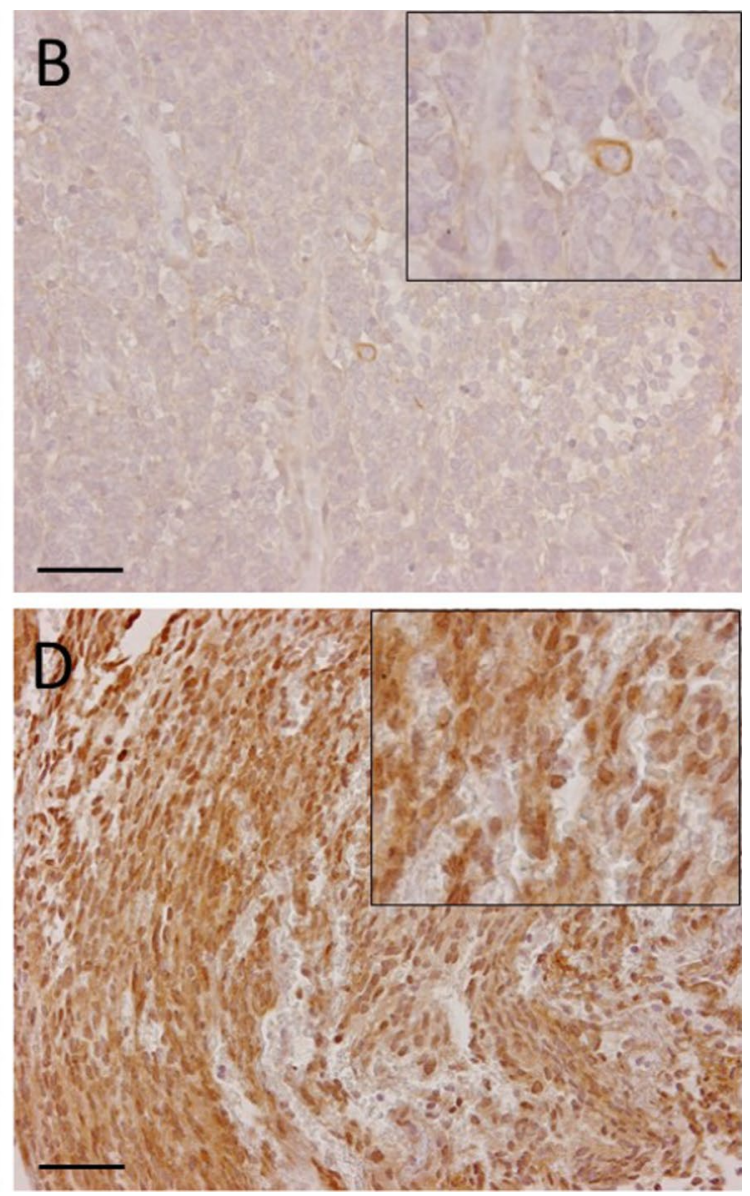

score 2 and grade ++. D B7-H3 expression scored with score 3 and grade +++ . Right corner corresponding to the inset. Original magnification $\times 20$, insets $\times 40$, scale bar $50 \mu \mathrm{m}$ 


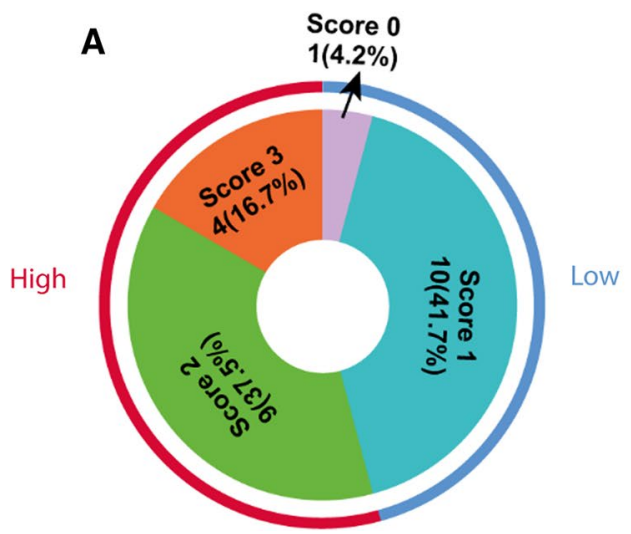

Fig. 2 Classification of medulloblastoma. A Classification of different intensity scores $(0,1,2,3)$ for B7-H3. Score 2 and score 3 defined as high expression of B7-H3 ( $n=13$, outside red line), score 0 and score 1 defined as low expression of B7-H3 $(n=11$, outside

Table 2 Correlation between B7-H3 and infiltrating immune cells

\begin{tabular}{|c|c|c|c|c|c|}
\hline \multirow{2}{*}{$\begin{array}{l}\text { Infiltrating immune } \\
\text { cells }\end{array}$} & \multicolumn{4}{|c|}{ B7-H3 score } & \multirow[t]{2}{*}{$p$ values } \\
\hline & Low & Ratio (\%) & High & Ratio (\%) & \\
\hline \multicolumn{6}{|l|}{ CD3+ } \\
\hline Low infiltrating & 3 & 25 & 9 & 75 & \multirow[t]{2}{*}{$0.041 *$} \\
\hline High infiltrating & 8 & 66.7 & 4 & 33.3 & \\
\hline \multicolumn{6}{|l|}{ CD4+ } \\
\hline Low infiltrating & 3 & 27.3 & 8 & 72.7 & \multirow[t]{2}{*}{0.093} \\
\hline High infiltrating & 8 & 61.5 & 5 & 38.5 & \\
\hline \multicolumn{6}{|l|}{$\mathrm{CD} 8+$} \\
\hline Low infiltrating & 4 & 33.3 & 8 & 66.7 & \multirow[t]{2}{*}{0.219} \\
\hline High infiltrating & 7 & 58.3 & 5 & 41.7 & \\
\hline \multicolumn{6}{|l|}{ CD20+ } \\
\hline Low infiltrating & 4 & 33.3 & 8 & 66.7 & \multirow[t]{2}{*}{0.219} \\
\hline High infiltrating & 7 & 58.3 & 5 & 41.7 & \\
\hline \multicolumn{6}{|l|}{$\mathrm{NKp} 46+$} \\
\hline Low infiltrating & 5 & 35.7 & 9 & 64.3 & \multirow[t]{2}{*}{0.239} \\
\hline High infiltrating & 6 & 60 & 4 & 40 & \\
\hline \multicolumn{6}{|l|}{ FOXP3+ } \\
\hline Low infiltrating & 4 & 33.3 & 8 & 66.7 & \multirow[t]{2}{*}{0.219} \\
\hline High infiltrating & 7 & 58.3 & 5 & 41.7 & \\
\hline \multicolumn{6}{|l|}{$\gamma \delta \mathrm{TCR}+$} \\
\hline Low infiltrating & 1 & 10 & 9 & 90 & \multirow[t]{2}{*}{$0.002 * *$} \\
\hline High infiltrating & 8 & 80 & 2 & 20 & \\
\hline
\end{tabular}

Numbers and percentage of medulloblastoma patients were showed in different subgroups

${ }^{a} \mathrm{~A}$ Pearson Chi-square analysis was used to evaluate correlation between B7-H3 expression (score of intensity staining) and infiltrating immune cells. Score 2 and score 3 defined as high expression of B7-H3 $(n=13)$, score 0 and score 1 defined as low expression of $\mathrm{B} 7-\mathrm{H} 3(n=11)$

$* p<0.05, * * p<0.01$
B

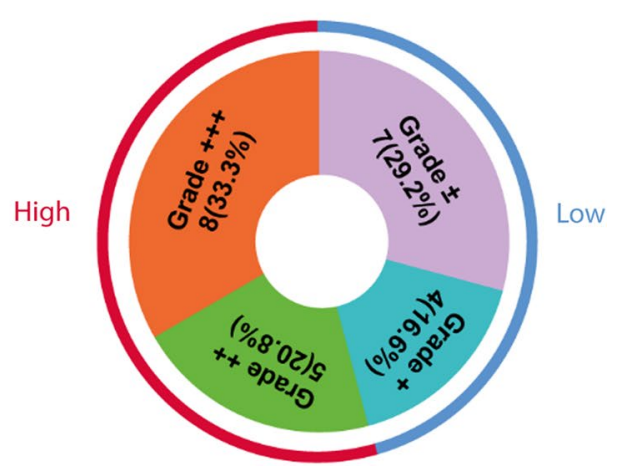

blue line). B Classification of B7-H3 positive staining in tumor cells. Grade ++ and grade +++ defined as high expression of B7-H3 $(n=13$, outside red line), grade \pm and grade + defined as low expression of B7-H3 ( $n=11$, outside blue line)

\section{Discussion}

We showed that immune checkpoint B 7-H3 is differentially expressed by the large majority of pediatric MB. It would have been of interest to determine whether B7-H3 expression could be used as an independent prognostic marker. However, the amount of patient cases available are too low to execute proper multi-variate statistical analyses. Nevertheless, our data further warrant the development of novel immunotherapeutic methods for children with incurable, metastatic, or chemo-resistant MB. First, B7-H3 may serve as a novel immune checkpoint inhibitor target for MB. To date, little is known about the molecular interactions, receptor(s), and biological functions of B7-H3 in cancer. However, B7-H3-deficient mice, or mice treated with an antagonistic antibody to B7-H3, showed reduced growth of many tumors, including lymphoma and lymphoblast [13]. Deficiency or blocking B7-H3 leads to increased CD8+T cell and NK cell function in tumor-bearing mice [13]. Fukushima et al. reported that B7-H3 negatively regulated both Th1- and Th2-mediated immune responses [14]. This is consistent with our finding of low $\mathrm{CD} 3+\mathrm{T}$ cell influxes when B7-H3 expression scores are high. Clinical trials with B7-H3 blocking antibody $8 \mathrm{H} 9$, also in combination with PD-1 blockade, are currently ongoing for treating patients with recurrent metastatic neuroblastoma and desmoplastic small round cell tumors in the peritoneum [15]. The wide expression of $\mathrm{B} 7-\mathrm{H} 3$ on $\mathrm{MB}$ appeals to the exploration of immunotherapeutic targeting B7-H3 in MB as well. Second, CAR T cell therapy is an upcoming approach designed to arm cytotoxic $\mathrm{T}$ lymphocytes with a receptor that can recognize a surface protein on tumor cells [16]. For instance, CD19-directed CAR T cells have previously been successful in treating certain pediatric hematologic malignancies [16]. Likewise, B7-H3-directed CAR T cells can mediate 
significant regression of MB tumors in xenograft mouse models [7]. In the current study, we confirmed that checkpoint B7-H3 is differentially expressed by the large majority of pediatric MB, using whole tissue slides, and we related this for the first time to MB molecular subtype and immune cell infiltrates. Thus, B7-H3 CAR T cells could represent an interesting novel therapeutic option for children with incurable, metastatic, or chemo-resistant MB.

Acknowledgements This work was supported by a research grants from Cancer Foundation Koppie-Au and Foundation Team Doelbewust. The funders had no role in study design, data collection and analysis, decision to publish, or preparation of the manuscript.

Author contributions Conceptualization: NB; methodology: JFV, RB, WVanH; formal analysis an investigation: SL, GCP, LCvanV, JGS, RB, MM, WVanH; writing-original draft preparation: SL; writing-review and editing: SL, NB; funding acquisition: NB; supervision: NB.

\section{Declarations}

Conflict of interest The authors have declared that no competing interests exist.

Ethical approval The manuscript does not contain any studies with human participants or animals performed by any of the authors.

Informed consent Informed consent/ethical approval was not required.

Open Access This article is licensed under a Creative Commons Attribution 4.0 International License, which permits use, sharing, adaptation, distribution and reproduction in any medium or format, as long as you give appropriate credit to the original author(s) and the source, provide a link to the Creative Commons licence, and indicate if changes were made. The images or other third party material in this article are included in the article's Creative Commons licence, unless indicated otherwise in a credit line to the material. If material is not included in the article's Creative Commons licence and your intended use is not permitted by statutory regulation or exceeds the permitted use, you will need to obtain permission directly from the copyright holder. To view a copy of this licence, visit http://creativecommons.org/licenses/by/4.0/.

\section{References}

1. Goldstein AM, Yuen J, Tucker MA. Second cancers after medulloblastoma: population-based results from the United States and Sweden. Cancer Causes Control. 1997;8:865-71.

2. Liu X, Ding C, Tan W, Zhang A. Medulloblastoma: molecular understanding, treatment evolution, and new developments. Pharmacol Ther. 2020;210:107516.

3. Brahmer JR, Tykodi SS, Chow LQ, Hwu WJ, Topalian SL, Hwu $\mathrm{P}$, et al. Safety and activity of anti-PD-L1 antibody in patients with advanced cancer. N Engl J Med. 2012;366:2455-65.
4. Goldberg SB, Gettinger SN, Mahajan A, Chiang AC, Herbst RS, Sznol M, et al. Pembrolizumab for patients with melanoma or non-small-cell lung cancer and untreated brain metastases: early analysis of a non-randomised, open-label, phase 2 trial. Lancet Oncol. 2016;17:976-83.

5. Hashimoto Y, Penas-Prado M, Zhou S, Wei J, Khatua S, Hodges TR, et al. Rethinking medulloblastoma from a targeted therapeutics perspective. J Neurooncol. 2018;139:713-20.

6. Gregorio A, Corrias MV, Castriconi R, Dondero A, Mosconi M, Gambini C, et al. Small round blue cell tumours: diagnostic and prognostic usefulness of the expression of B7-H3 surface molecule. Histopathology. 2008;53:73-80.

7. Majzner RG, Theruvath JL, Nellan A, Heitzeneder S, Cui Y, Mount CW, et al. CAR T cells targeting B7-H3, a pan-cancer antigen, demonstrate potent preclinical activity against pediatric solid tumors and brain tumors. Clin Cancer Res. 2019;25:2560-74.

8. Purvis IJ, Avilala J, Guda MR, Venkataraman S, Vibhakar R, Tsung AJ, et al. Role of MYC-miR-29-B7-H3 in medulloblastoma growth and angiogenesis. J Clin Med. 2019;8:1158.

9. Kanchan RK, Perumal N, Atri P, Chirravuri Venkata R, Thapa I, Klinkebiel DL, et al. MiR-1253 exerts tumor-suppressive effects in medulloblastoma via inhibition of CDK6 and CD276 (B7-H3). Brain Pathol. 2020;30:732-45.

10. Maachani UB, Tosi U, Pisapia DJ, Mukherjee S, Marnell CS, Voronina J, et al. B7-H3 as a prognostic biomarker and therapeutic target in pediatric central nervous system tumors. Transl Oncol. 2020;13:365-71.

11. Vermeulen JF, Van Hecke W, Adriaansen EJM, Jansen MK, Bouma RG, Villacorta Hidalgo J, et al. Prognostic relevance of tumor-infiltrating lymphocytes and immune checkpoints in pediatric medulloblastoma. Oncoimmunology. 2018;7:e1398877.

12. Vermeulen JF, van Hecke W, Spliet WG, Villacorta Hidalgo J, Fisch P, Broekhuizen R, et al. Pediatric primitive neuroectodermal tumors of the central nervous system differentially express granzyme inhibitors. PLoS One. 2016;11:e0151465.

13. Lee YH, Martin-Orozco N, Zheng P, Li J, Zhang P, Tan H, et al. Inhibition of the B7-H3 immune checkpoint limits tumor growth by enhancing cytotoxic lymphocyte function. Cell Res. 2017;27:1034-45.

14. Fukushima A, Sumi T, Fukuda K, Kumagai N, Nishida T, Yamazaki T, et al. B7-H3 regulates the development of experimental allergic conjunctivitis in mice. Immunol Lett. 2007;113:52-7.

15. Kramer K, Kushner BH, Modak S, Pandit-Taskar N, Smith-Jones $\mathrm{P}$, Zanzonico $\mathrm{P}$, et al. Compartmental intrathecal radioimmunotherapy: results for treatment for metastatic CNS neuroblastoma. J Neurooncol. 2010;97:409-18.

16. Mackall CL, Merchant MS, Fry TJ. Immune-based therapies for childhood cancer. Nat Rev Clin Oncol. 2014;11:693-703.

Publisher's Note Springer Nature remains neutral with regard to jurisdictional claims in published maps and institutional affiliations. 